\title{
A metallurgical and thermal analysis of Inconel 625 electron-beam welded joints
}

\author{
L. Romanin, P. Ferro, A. Fabrizi \\ University of Padova, Italy \\ luca.romanin@phd.unipd.it \\ paolo.ferro@unipd.it, https://orcid.org/0000-0001-8682-3486 \\ alberto.fabrizi@unipd.it \\ F. Berto \\ University of Trondheim (NTNU), Norway \\ filippo.berto@ntnu.no,bttps://orcid.org/0000-0002-4207-0109
}

\begin{abstract}
Inconel 625 is a nickel-based superalloy that finds application in many industrial sectors thanks to its high strength, excellent fabricability, and outstanding corrosion resistance. It is characterized by a good weldability and often used in the as-welded conditions.

In the following, a metallurgical and thermal analysis of Inconel 625 ElectronBeam welded joints is described. The thermal analysis was supported by a numerical model that uses a superimposition of a spherical and a conical shape heat source with Gaussian power density distribution in order to reproduce the nail-shape of the fusion zone. The heat source parameters were calibrated by using experimental data coming from metallurgical observations and temperature measurements. Numerical and experimental results were found in good agreement.
\end{abstract}

KEYwORDS. Welding; Inconel 625; Thermal Analysis; Numerical Modelling; Microstructure.

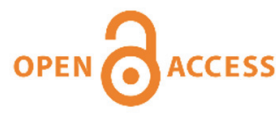

Citation: Romanin, L., Ferro, P., Fabrizi, A., Berto, F., A metallurgical and thermal analysis of Inconel 625 electron-beam welded joints, Frattura ed Integrità Strutturale, 50 (2019) 251-263.

Received: 27.07.2019

Accepted: 17.08 .2019

Published: 01.10.2019

Copyright: (C) 2019 This is an open access article under the terms of the CC-BY 4.0, which permits unrestricted use, distribution, and reproduction in any medium, provided the original author and source are credited.

\section{INTRODUCTION}

$\mathrm{N}$

ickel-base superalloys for aerospace and industrial applications are of great interest in the materials research field. Their creep and oxidation resistance properties make them the base material for aero-engine components in hot sections, such as turbine discs, blades and casings. In such applications, the possibility to repair or assemble different parts by welding is a fundamental task for the design and industrialization of these products. Therefore, studies related to the weldability of this kind of material are of primary importance in order to obtain sound welds. Their hot cracking sensitivity, arising from a synergy of phenomena such as wide solidification temperature interval, chemical 
composition and thermal stresses, is the most important problem to solve since it enormously compromises the low cycle fatigue resistance [1]. For this reason, high power density welding technologies [2-4], with a particular attention to electron-beam welding (EBW), are the most favorite. In fact, they ensure a very narrow fusion zone (FZ) as well as heataffected zone (HAZ) and a reduction in distortion and residual stresses. In particular, the high vacuum, which characterizes the EBW, avoids material contamination and yields deep penetration. Experimental results carried out on a limited number of nickel-base alloys [4-6], showed that it is possible to obtain sound welds by optimizing the welding speed, pre-heating, beam focus and welding current. Thanks to computer development, it is possible to avoid expensive experimental work and use numerical simulation for predicting the stress evolution during welding [7,8]. A typical keyhole weld is usually accompanied by a distinct 'nail head' appearance at the top. The first attempts to model this shape were analytical. Klykow et al. [9] combined a depth source, which describes the keyhole effects and the energy related transfer, and a surface source, representing the plume radiation on the workpiece surface. Both sources had a Gaussian power distribution. Here, it was found that, in laser welding, plasma may be regarded as an independent heat source in the surface, and the laser beam as a volume source resulting in a dagger shape form of the penetration zone. Steen et al. [10] combined the point and line source of Rosenthal [11] to model more effectively a keyhole weld and estimate the power actually absorbed by the weld. The line source represents absorption down the keyhole and the point source represents the plasma radiation from the plume. Bonollo et al. [12] studied the effect of the operative pressure on the weld beads of different materials welded using a $\mathrm{CO}_{2}$ laser beam. An analytical model of the process was developed using two heat sources that allowed the quantitative evaluation of the power distribution between the keyhole and the plume. Experimental and analytical results were in good agreement. Instead of using two sources, Binda et al. [13] proposed a semi-empirical model of the temperature field in laser welding, based on a modification of the Rosenthal solution. The hypothesis of a constant heat rate along the thickness was replaced by a generic unknown function, to be determined from experimental data.

All the analytical models do not consider the variation of the thermal properties with temperature and phase change. Besides, they are not able to predict the thermal and residual stress fields induced by the welding process. For this reason, numerical thermo-mechanical models were developed. In high power density welding technology, a conical source shape with Gaussian power density distribution is often used [7,14]. Though the experimental and numerical results are in sufficient overall agreement, a single source is insufficient to reproduce the correct 'nail' shape of the fusion zone and thus the local stress development at the FZ-HAZ interface.

Du et al. [15], developed a mathematical model for flow simulation of full penetration laser beam welding of titanium alloy. The model is based on a plane heat source on the top surface and a cylindrical heat source along the z-direction, which take into account the plasma effects and the keyhole absorption. The model, based on the numerical solution of the fluid mechanics equations, gave a good prediction of the FZ shape but was not used for the stress evaluation arising from the welding process.

Nickel-base superalloys suffer, above all, from weld-cracking tendency [5]. The idea to correlate weld cracking with the stress-strain evolution during weld cooling was developed by Feng et al. [16]. They considered only transversal and longitudinal stresses as a function of weld cooling. Cracking will be promoted if a weak microstructure and/or a sufficiently high tensile stress exists. However, the model does not consider the correct FZ shape of the bead and the 3D distribution of the stress field. Dye et al. [17] proposed a numerical method for the prediction of the processing conditions that are liable for producing defects during welding such as constitutional liquation, solidification cracking and a centreline grain formation. In particular, solidification cracking is assumed to arise due to the generation of a positive transverse stress at the point behind the heat source where the liquid fraction is still significant. The model was applied to TIG welding of Inconel 718 using a semi-analytical solution for the temperature field and a thermal elasto-plastic analysis in two-dimension, assuming a state of plane stress. In such a way, the real shape of the FZ through the thickness and thus the stress component in z-direction was neglected. For this reason, the model is not suitable for the prediction of microfissures formation along the thickness.

It is noted that a lack of knowledge is still present in the specific literature on EBW process applied to alloy systems such as Nickel-base superalloys. Mayor [18] investigated the characteristics of Inconel 718 and 706 joints, though welded by GTAW (gas tungsten-arc welding), finding an excellent weldability and good tensile strength at both room and elevated temperature. The thermal effects of welding operations have been observed to affect the desirable structure of the heattreatable alloys by producing heat-affected zones with poor stress-rupture properties. The properties are substantially restored to the required level, however, by post-weld heat-treatment involving, in general, solution and ageing treatments at conventional temperatures. In this case, age hardening treatment following welding was found to be more than adequate, without a need for a re-solution treatment. Ferro et al. [19] investigated the electron beam welding of Inconel 706. They found a good agreement between thermal-mechanical analysis and experimental data. The numerical model was 
helpful in correlating microfissures occurring at the grain boundaries, under the nail head of the bead, with process parameters. Laki et al. [20] studied the EBW of 30HGSA steel using a conical heat source. They also found good consistency with empirical data. In a more recent investigation, Laki et al. [21], from a series of 49 weld experiments, created a Partial Least Square model of the FZ and subsequently defined the heat source utilizing mesh segments and constant power density on each segment. The phenomenological approach has been used by Palmer et al. [22] when they simulated the EBW of 304L stainless steel. They included thermal conductivity and viscosity to account for enhanced heat and mass transfer due to turbulence in the weld pool and found that convective heat transfer was very significant in determining the weld geometry. However, this type of analysis is not convenient for a subsequent mechanical analysis because it involves results mapping from a Finite Volume Method to a Finite Element Method code.

It is pointed out that only few researchers have investigated in the past the effects of high-power density welding techniques on Ni-base wrought superalloys. Some works can be found about laser welds in wrought Waspaloy [2] but specific information on the high-energy beam welding of other Ni-based superalloy have not yet fully established.

In the recent literature some works focused their attention to the precipitation of Laves phase particles [23] or equilibrium and metastable phase/grain morphology [24] during laser additive manufacturing or rapid solidification of Ni-based superalloys. Such work uses quite complex models solved by the phase-field method or multi-scale model combining the finite element method and stochastic analysis. The JMAK-type model was instead applied by different researcher [25-27] with the aim to predict the microstructure evolution in nickel-based superalloys. In particular the Avrami exponent for $\gamma^{\prime}$ precipitation was determined to be in the 1.5-2.3 range, suggesting spherical or irregular growth. A methodology was also developed to take into account the temperature dependence of the rate coefficient $k(T)$ in the non-isothermal JMA equation. Finally, it is interesting to mention a recent review paper about welding characteristics of aerospace materials that highlight the potentiality of high-power density welding processes (LW, EBW) compare to the traditional arc welding technologies [28].

In this work, a numerical model of EBW of Inconel 625 has been developed. The phenomenological approach proposed is based on the calibration of the source parameters on the basis of macrographs and temperature measurements. Experimental and numerical results were found in good agreement and suitable for a future mechanical analysis. The obtained results will be used also for a further development of the thermal-metallurgical model that includes phase precipitation and dissolution [29]. Moreover, the utilized welding process did not produce any grain growth or detrimental phases such as $\sigma, \mu$ and Laves Phases in more than trace amounts as it will be described afterwards. Hardness measurement has been presented, as well.

\section{Material ANd EXPerimental Procedure}

he chemical composition of the specimens has been measured by Energy Dispersive X-ray spectroscopy (EDS) and is summarized in Tab. 1.

\begin{tabular}{ccccccccccc}
\hline $\mathrm{Ni}$ & $\mathrm{Cr}$ & $\mathrm{Fe}$ & $\mathrm{Mo}$ & $\mathrm{Nb}+\mathrm{Ta}$ & $\mathrm{C}$ & $\mathrm{Mn}$ & $\mathrm{Si}$ & $\mathrm{Al}$ & $\mathrm{Ti}$ & $\mathrm{Co}$ \\
58.30 & 20.39 & 3.94 & 8.91 & 3.76 & - & - & 0.32 & - & 0.22 & - \\
\hline
\end{tabular}

Table 1. Chemical composition calculated by EDS on specimen Test $1(\mathrm{wt} \%)$

Four butt-welded joints were produced, each one obtained by electron beam welding two plates which dimensions are 16 $\mathrm{mm} \times 72 \mathrm{~mm} \times 2.5 \mathrm{~mm}$ (Fig. 1). Since no filler material has been used, the joining edges have been prepared to obtain the best contact. In order to validate thermal analysis results, two K-type thermocouples have been inserted at $2.5 \mathrm{~mm}$ and 6 $\mathrm{mm}$ far from the weld seam, as shown in Fig. 1. The holes, with a diameter of $1 \mathrm{~mm}$, have been realized with Electro Discharge Machining. Picotech TC-08 Termocouple Data Logger has been used for data recording.

The plates to be welded were first clamped as shown in Fig. 2 and then tack welded in six points, one every $10 \mathrm{~mm}$, in order to avoid plates detachment due to thermal expansion. Weld tacking increased also the overall specimen temperature because of the small mass of the specimens.

Welding tests have been carried out according to the parameters defined in Tab. 2 and using a vacuum chamber with a pressure of 4 10-4 mbar.

Full penetration was not reached in the first $10 \mathrm{~mm}$ of the welding line. However, starting and ending points are not taken into account in this work. In Tests 2 and 3 , the current proved to be too high since a crater formed at about $2 / 3$ of the 
welding line. Because starting and ending lack of full penetration could be neglected, the current has been therefore slightly lowered to $14.5 \mathrm{~mA}$ in the last welding test (Test 4). Optical and Scanning Electron Microscopes (with microprobe EDS) were used for the metallurgical investigation. For optical microscope $(\mathrm{OM})$ analysis, the specimens have been etched with a solution made of nitric acid $\left(\mathrm{HNO}_{3}\right)$ and chloridic acid $(\mathrm{HCl})(1 / 3$ parts in volume). Precipitates were analyzed in terms of shape, dimension and chemical composition. Detected X-ray spectra have been compared with previous ones published in literature with the aim to find matching patterns and recognize phases with a reasonable degree of accuracy. Micro-segregation patterns across the dendritic substructure of the FZ were finally checked.
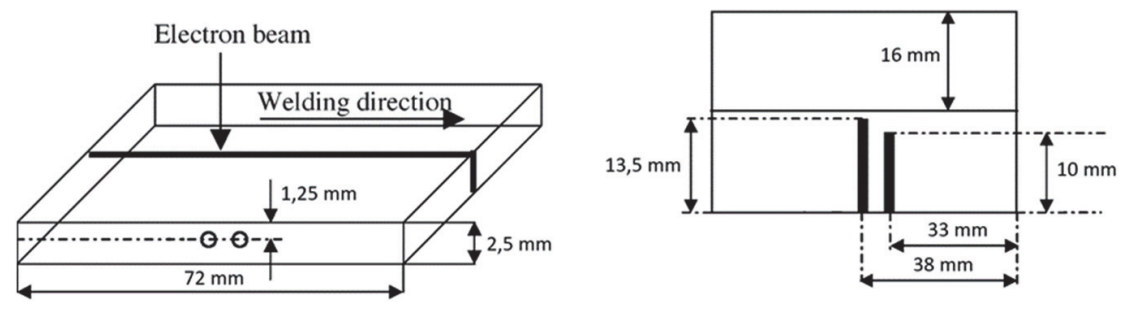

Figure 1: 3D representation (a) and top view (b) of the specimen showing the holes position for the thermocouples.

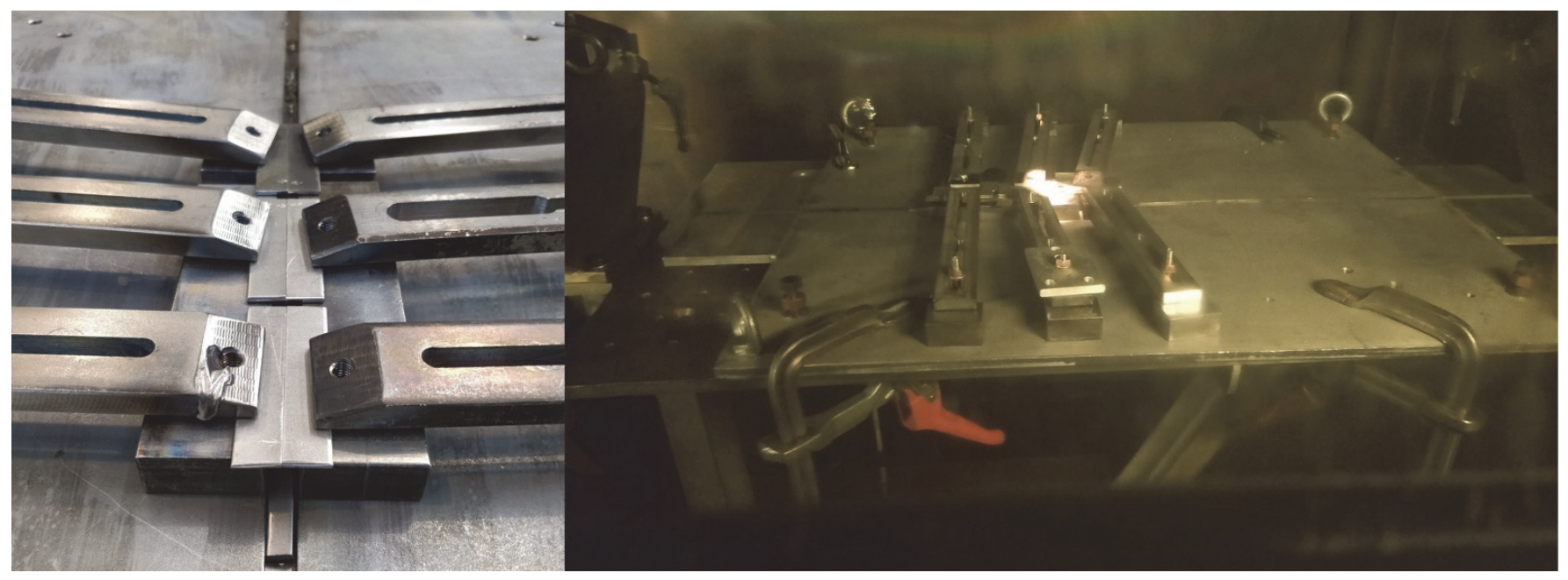

Figure 2: Clamping configuration and EBW in progress.

\begin{tabular}{cccccccc}
\hline & $\begin{array}{c}\text { Accelerating } \\
\text { voltage }(\mathrm{kV})\end{array}$ & $\begin{array}{c}\text { Beam current } \\
(\mathrm{mA})\end{array}$ & $\begin{array}{c}\text { Focus } \\
\text { current }(\mathrm{mA})\end{array}$ & $\begin{array}{c}\text { Spot } \\
\text { diam. } \\
(\mathrm{mm})\end{array}$ & $\begin{array}{c}\text { Freq. } \\
(\mathrm{Hz})\end{array}$ & $\begin{array}{c}\text { Speed } \\
(\mathrm{mm} / \mathrm{s})\end{array}$ & Notes \\
Test 1 & 150 & 15 & 347 & 1.5 & 300 & 12 & - \\
Test 2 & 150 & 15 & 347 & 1.5 & 300 & 12 & - \\
Test 3 & 150 & 15 & 347 & 1.5 & 300 & 12 & - \\
Test 4 & 150 & 14,5 & 347 & 1.5 & 300 & 12 & Thermocouples \\
\hline
\end{tabular}

Table 2: EBW tests parameters

\section{EXPERIMENTAL RESULTS}

\section{Metallurgical results}

The FZ shape is shown in Fig. 3a. The grains are dendritic and oriented along the heat flux direction (Fig. 3b).

Fig. 4 reveals both the characteristic epitaxial grains grow at the FZ/HAZ interface and a narrow HAZ of about $0.2 \mathrm{~mm}$. Grains, in the parent material, maintains an equiassic morphology. No grain growth was detected in the HAZ, as it could be observed in Fig. 4. This is because EBW is characterized by a rapid heating and cooling, greatly reducing the material 
alteration compared to arc welding. It is also noted that in the heat affected zone, grains boundaries are less evident than those in the parent material (PM).

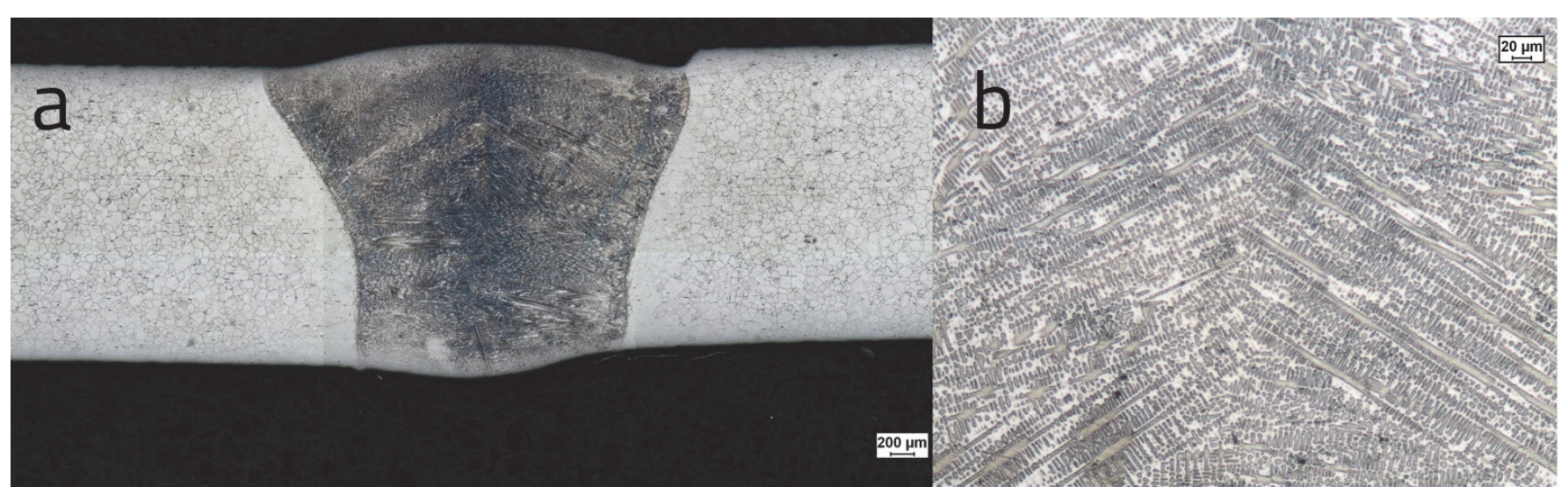

Figure 3: FZ shape (a) and microstructure (b)

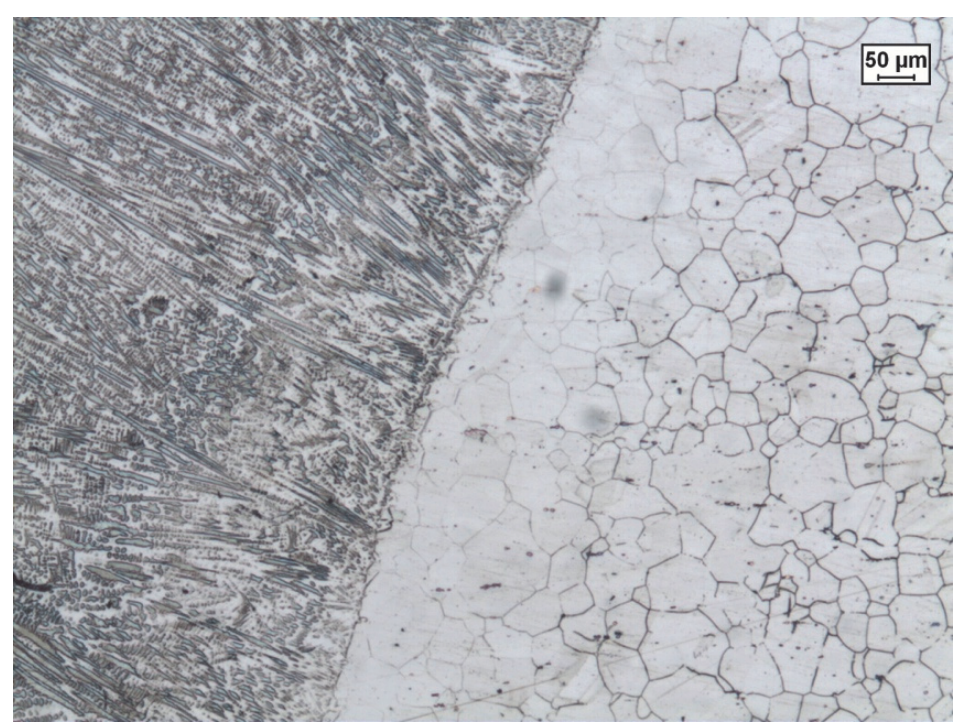

Figure 4: HAZ details

Grain boundaries in the PM were carefully analyzed by SEM (Fig. 5).

A dark precipitate (Label 1), of about $3 \mu \mathrm{m}$, and a series of lighter and smaller precipitates (Label 2) with dimensions in the order of $0.1 \mu \mathrm{m}$ were detected (Fig. 5b). The dark precipitate contains mostly Titanium and Niobium (Fig. 5c) and is therefore classified, according to literature [30], as MC ( $\mathrm{TiC}$ ) carbide. The smaller precipitates (Label 2) are distributed along the grain boundaries and have a fine globular aspect. Moreover, they contain mostly molybdenum and chromium like the $\mathrm{M}_{23} \mathrm{C}_{6}$ carbides in references [31,32]. Niobium carbides and Leave's precipitates are also found in the PM as shown in Fig. $6[30,33]$.

No other type of precipitate has been found in the parent material.

By comparing the spectra coming from EDS measurements in the dendritic and interdendritic zones, Mo was found to segregate in the interdendritic space (label 10) (Fig. 7). For the sake of simplicity, spectra coming from points 8 and 9 of Fig. 7 are not reported in this work. Anyway, because of their content of nickel, molybdenum, niobium and chromium, they were classified as Leave's phase $[33,34]$. 

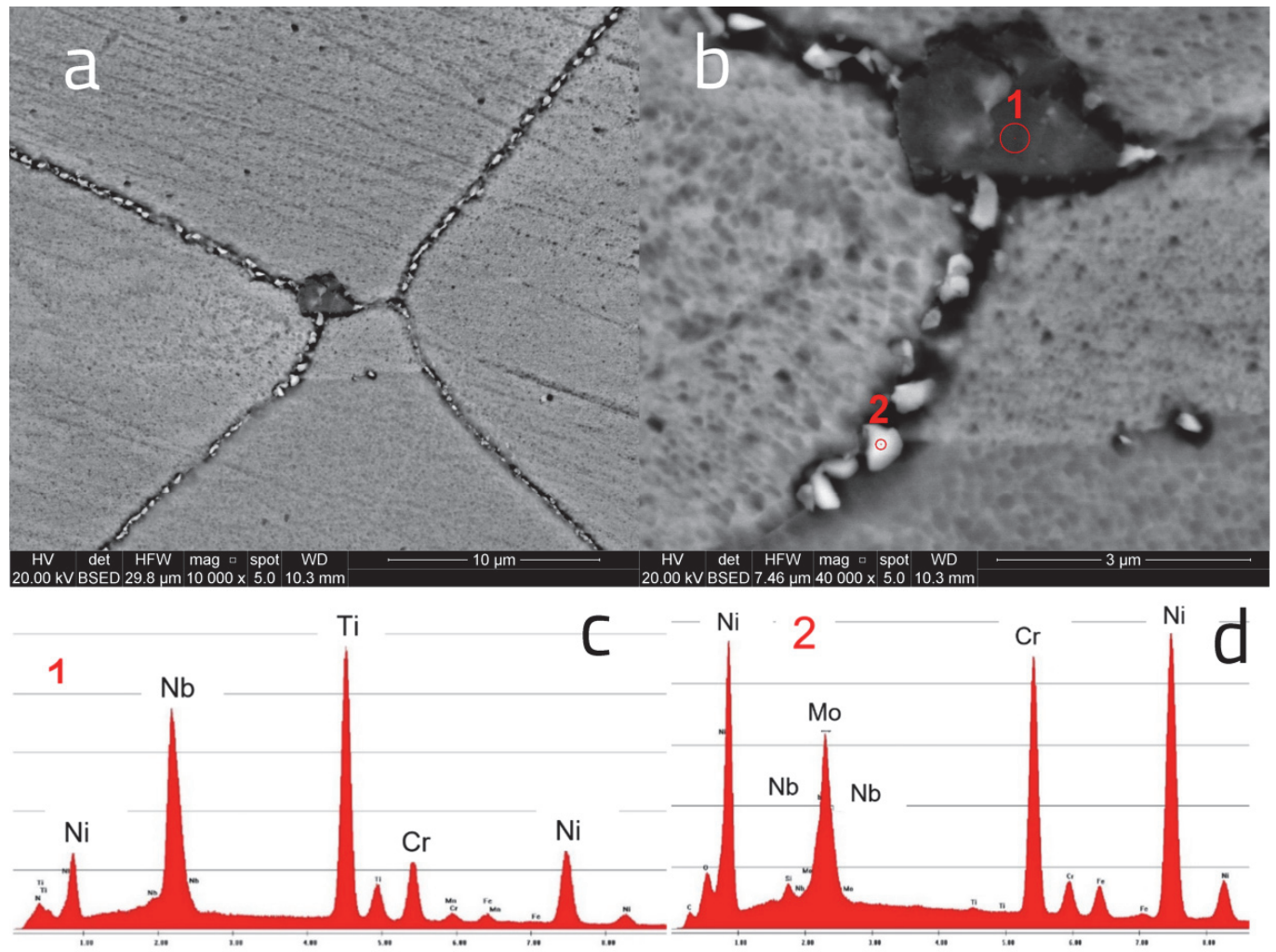

Figure 5: Grain boundaries precipitates at different magnifications (10000x (a), 40000x (b)) and EDS spectra in points 1 (c) and 2 (d)

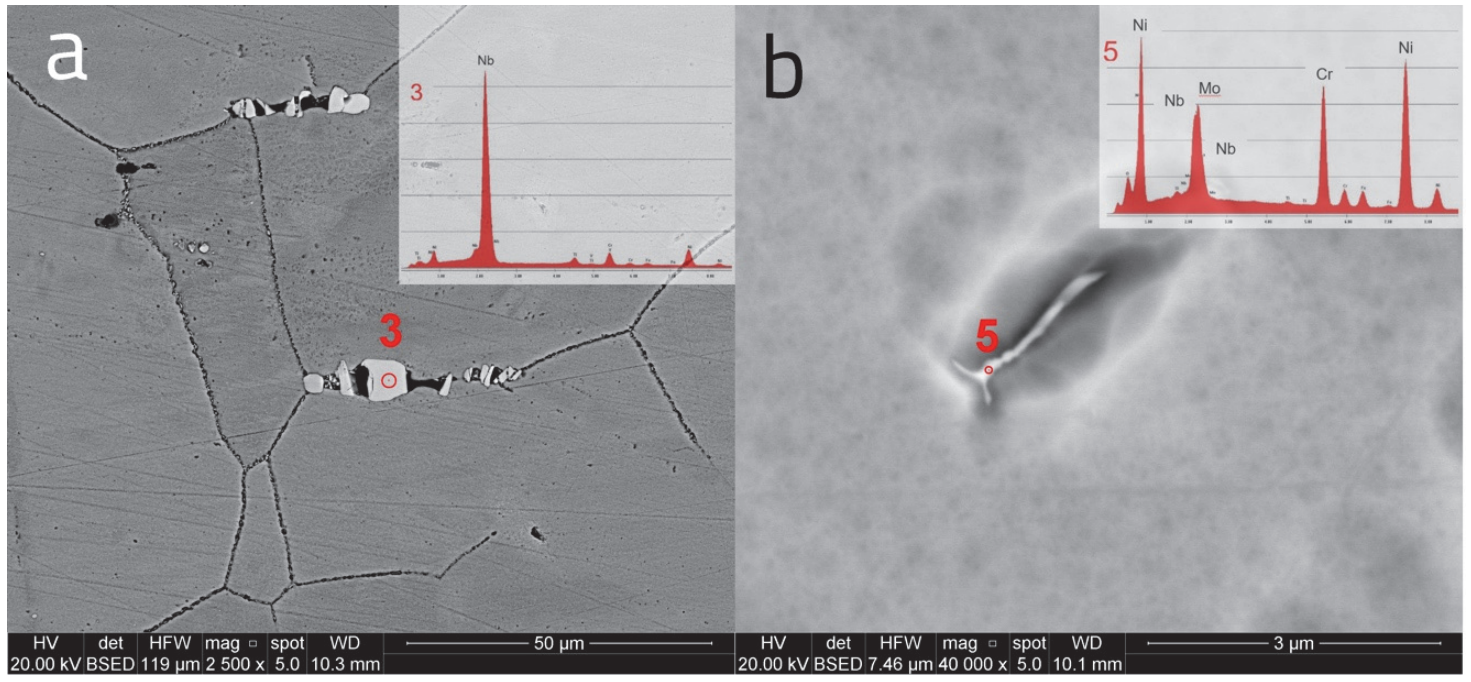

Figure 6: Precipitates in PM: NbC (a), Leave's phase (b)

\section{Microhardness profiles}

Two Vickers microhardness profiles across the FZ are shown in Fig. 8. The FZ extends from about $-1500 \mu \mathrm{m}$ to +1700 $\mu \mathrm{m}$. In that region, hardness is more variable reflecting the inhomogeneous dendritic microstructure. However, microhardness results are contained around a mean value of about $243 \mathrm{HV}$. This confirms both the very narrow HAZ and the good electron beam weldability of the analyzed alloy. As a matter of fact, no microhardness profile depressions were observed that could suggest a sensitive reduction of welded joints mechanical properties compared to those of the parent metal. 


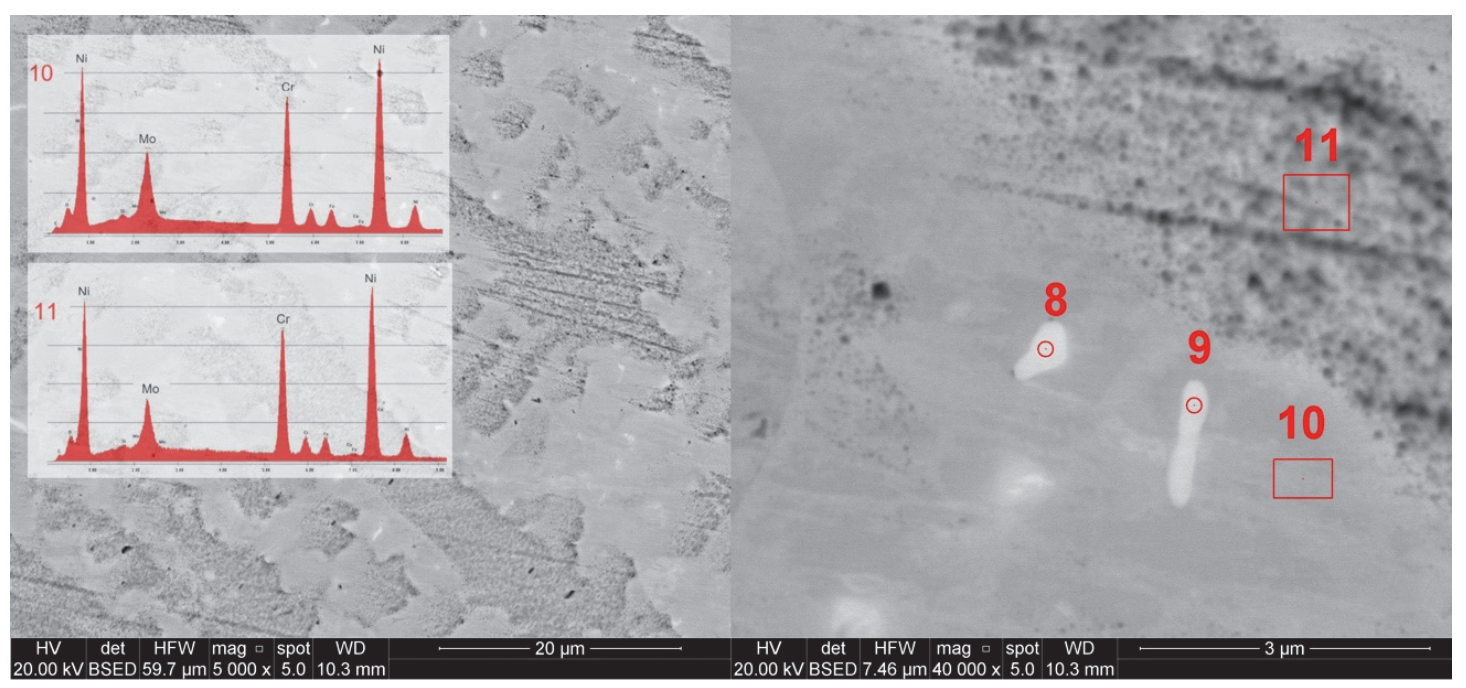

Figure 7: Precipitates and Mo segregation in FZ.

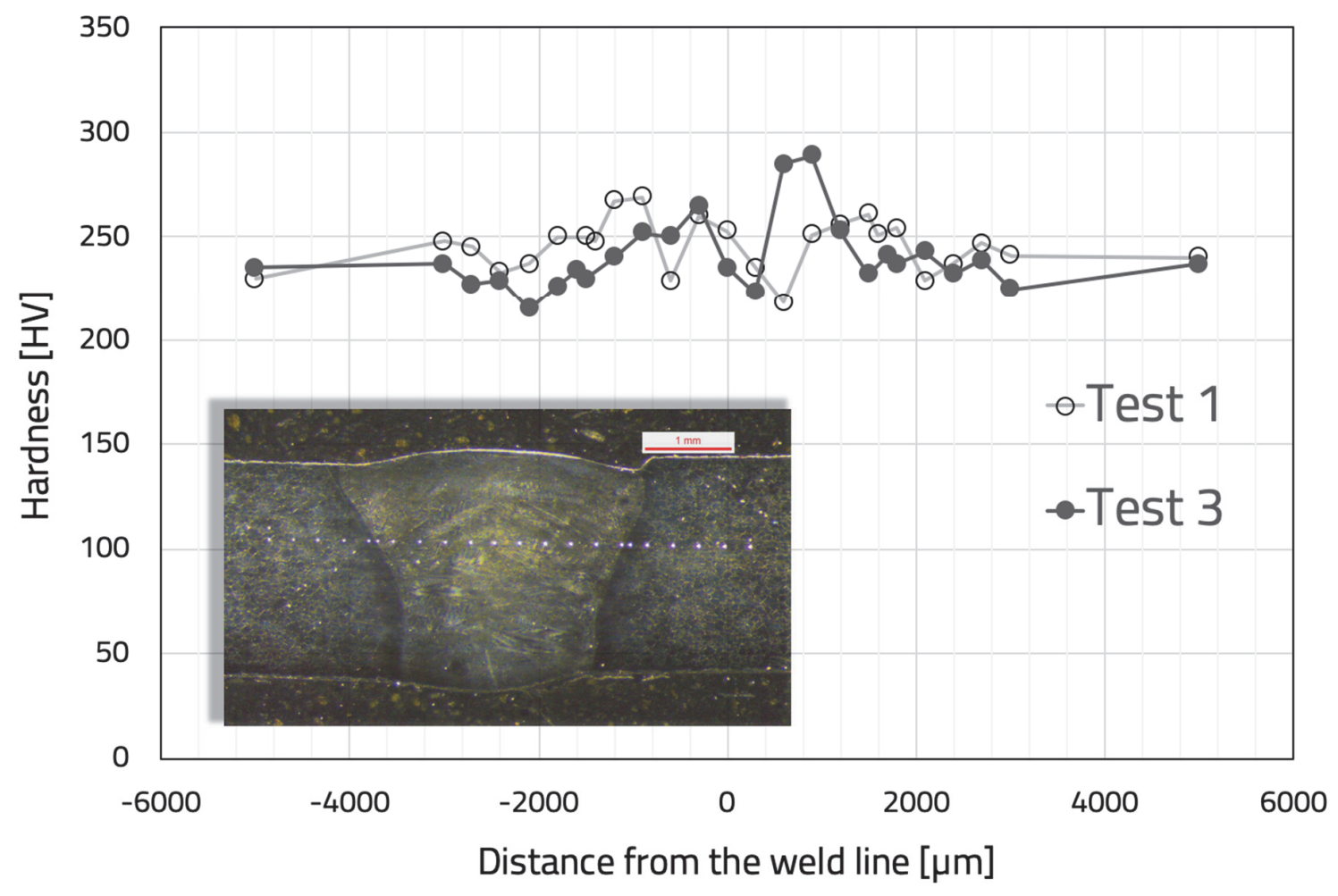

Figure 8: Microhardness profiles

\section{NUMERICAL MODEL}

A non-linear thermal transient analysis of the electron beam welding process has been performed. The fast motion and the extremely high power concentration of the heat source cause severe temperature gradients and heating/cooling rates which have to be captured by a fine mesh and a small time-step. Taking advantage of geometrical and load symmetry, only one plate has been modelled. A time step of $0.05 \mathrm{~s}$ was set during the passage of the heat source over the piece. 
The thermal model has been validated using data of the specimen named "Test 4" in which two thermocouples have been inserted and a macrograph of the middle cross section has been obtained (Fig. 3a).

About 40000 3D linear elements were used. The mesh has been graded both in the transversal and in the longitudinal direction to optimize the number of elements. On the symmetry plane, along the thickness, 8 elements of around $0.3 \mathrm{~mm}$ have been used (Fig. 9, cross section). Moving far from the weld bead, gradually, only 4 elements along the thickness have been used.

In the longitudinal direction, the mesh is finer at the start and end of the weld seam and coarser in the middle of the plate where thermal condition can be assumed quasi-stationary (Fig. 9, top view). For this reason, in the longitudinal direction, a parabolic bias has been imposed to have a finer mesh in the starting and ending regions because of the higher temperature gradients due to the start and stop of the weld. The elements size ranges from $0.17 \mathrm{~mm}$ (welding start/end) to $0.77 \mathrm{~mm}$ in the middle of the plate.
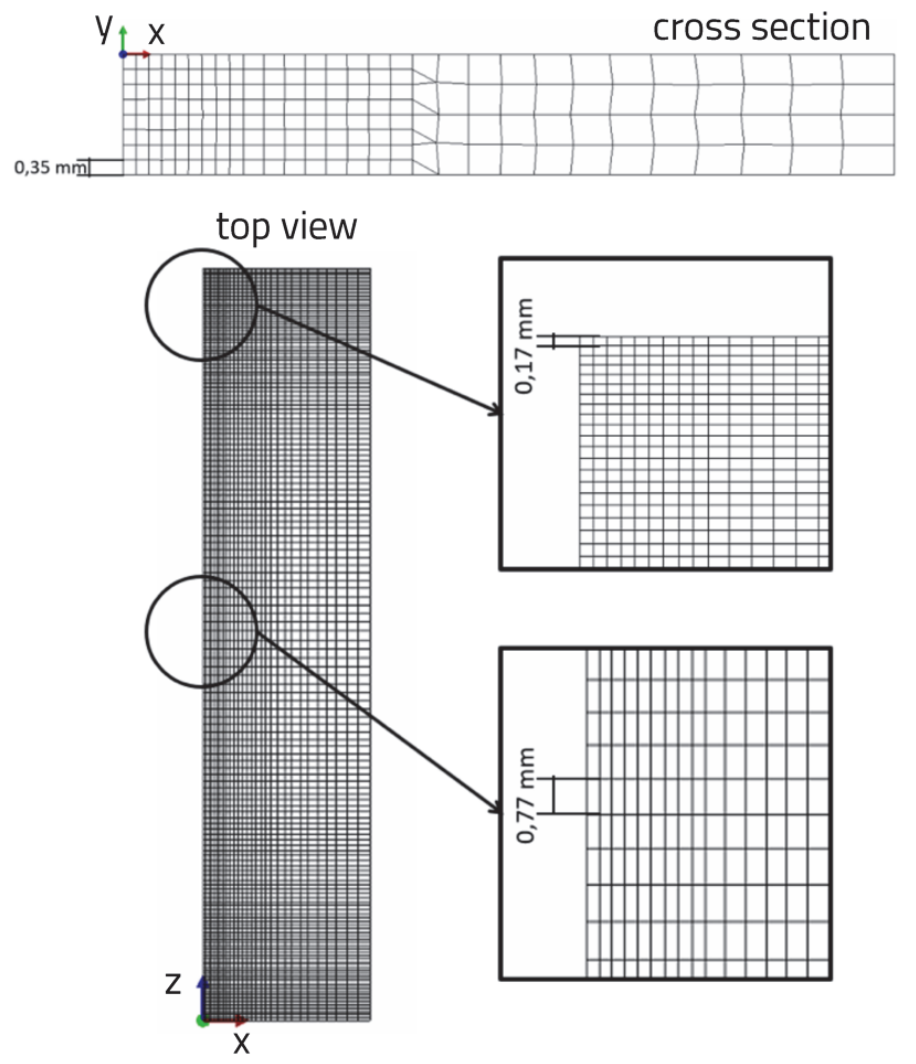

Figure 9: Mesh of the numerical model

\section{Boundary Conditions}

Heat loss by radiation and conduction trough the clamps has been taken into account. Thermal radiation was simulated by using the Stefan-Boltzman law, while the heat loss by conduction by using an equivalent convection coefficient. As a matter of fact, because of the small dimensions of the specimen, the effect of the clamps is non negligible and the advantage of using the convection coefficient is to avoid the modelling of the contact resistance which would have required a phenomenological calibration and introduced another source of error. The value of the convection coefficient was empirically determined to be $10 \mathrm{~W} / \mathrm{m}^{2}$, while the room temperature has been set to $25^{\circ} \mathrm{C}$.

The initial temperature has been set to $95^{\circ} \mathrm{C}$, according to experimental data. This is due to the tack welding operation carried out before EBW.

\section{Heat Source}

During EBW, in the beam impingement zone, a portion of material evaporates creating a cavity containing metallic plasma because of the high temperature reached. 
Various authors have studied the keyhole formation and evolution in EBW or laser welding by using CFD analysis with the aim to predict gas porosity. In this case, a phenomenological approach has been adopted that uses thermocouples data and micrographs of the FZ to calibrate a power density distribution function. In particular, the characteristic nail-shape of the FZ has been simulated by superimposing a spherical and a conical heat source.

The spherical heat source is defined by a constant power density distribution $\left(q_{0}\right)$ in the range between $r=0$ and $r=R_{1}$ (inner radius) and a linear power density decreasing from $R_{1}$ to $R_{2}$ (outer radius) (Eq. 1).

$$
q=\left\{\begin{array}{c}
q_{0} \quad \text { if } 0<r<R_{1} \\
q_{0} \frac{R_{2}-r}{R_{2}-R_{1}} \quad \text { if } R_{1} \leq r \leq R_{2}
\end{array}\right.
$$

The conical heat source, on the other hand, is characterized by a Gaussian power density distribution centered in its axis (Eq. 2)

$$
q=q_{0} e^{-\frac{r^{2}}{r_{0}^{2}}}
$$

In Eq. (2) $r^{2}=(z-v t)^{2}+x^{2}$ and $r_{0}=R_{e}-\left(R_{e}-R_{i}\right)\left(y_{e}-y\right) /\left(y_{e}-y_{i}\right)$ for $y_{i}<y<y_{e}$. The heat source moves along the $z$ axis with a speed $v$ ( $\mathrm{t}$ is the time). Fig. 10 illustrates the shape of the above defined power density distribution functions and their superposition.
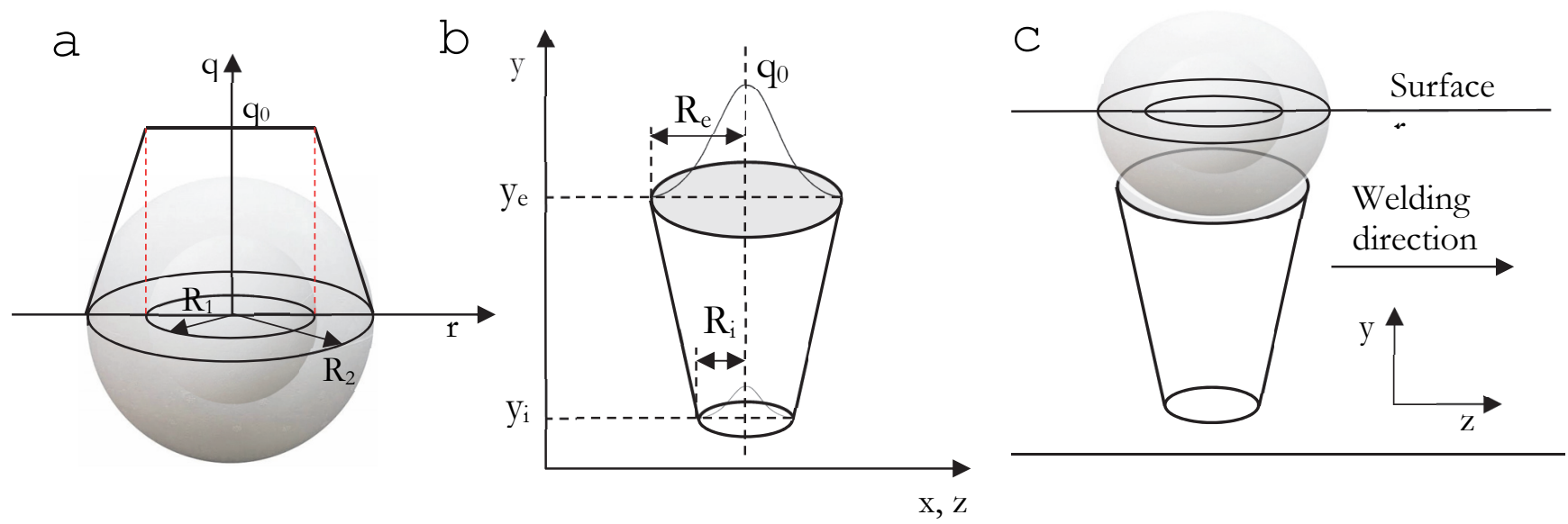

Figure 10: Spherical (a) and conical (b) power density distribution functions and their superposition (c).

The heat source parameters have been chosen comparing experimental and numerical results. The parameters obtained for the 'Test 4' are given in Tabs. 3 and 4 for the spherical and conical heat source, respectively.

\begin{tabular}{ccc}
\hline $\mathrm{q}_{0}\left[\mathrm{~W} / \mathrm{mm}^{3}\right]$ & $\mathrm{R}_{1}[\mathrm{~mm}]$ & $\mathrm{R}_{2}[\mathrm{~mm}]$ \\
260 & 0.5 & 1.6 \\
\hline
\end{tabular}

Table 3: Spherical heat source parameters.

\begin{tabular}{ccccc}
\hline $\mathrm{q}_{0}\left[\mathrm{~W} / \mathrm{mm}^{3}\right]$ & $\mathrm{R}_{\mathrm{i}}[\mathrm{mm}]$ & $\mathrm{R}_{\mathrm{e}}[\mathrm{mm}]$ & $\mathrm{y}_{\mathrm{i}}[\mathrm{mm}]$ & $\mathrm{ye}_{\mathrm{e}}[\mathrm{mm}]$ \\
90 & 0.9 & 0.9 & -1.5 & -2.5 \\
\hline
\end{tabular}

Table 4: Conical heat source parameters. 
Fig. 11 shows a sufficient good matching between the FZ shape and dimension obtained by experiments with those calculated with the numerical model.

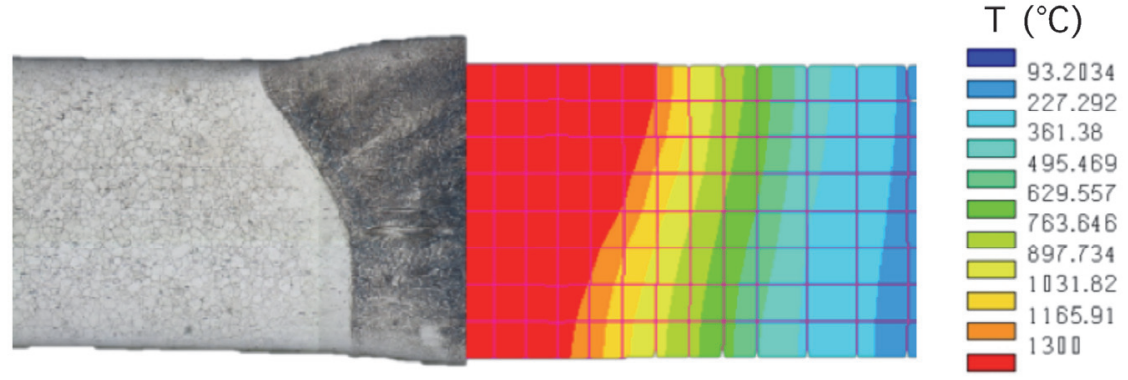

Figure 11: Comparison between the measured and predicted FZ (red area) in the middle cross section of the plate

\section{Material properties}

Thermal conductivity, density and specific heat versus temperature are shown in Fig. 12. Precipitates that forms during cooling have no effect on thermal properties. Since the effect of latent heat during solid to liquid (and vice-versa) transformation is neglectable compared to the high energy densities transferred from the electron beam to the workpiece, for the sake of simplicity, it was not taken into account during the simulation.

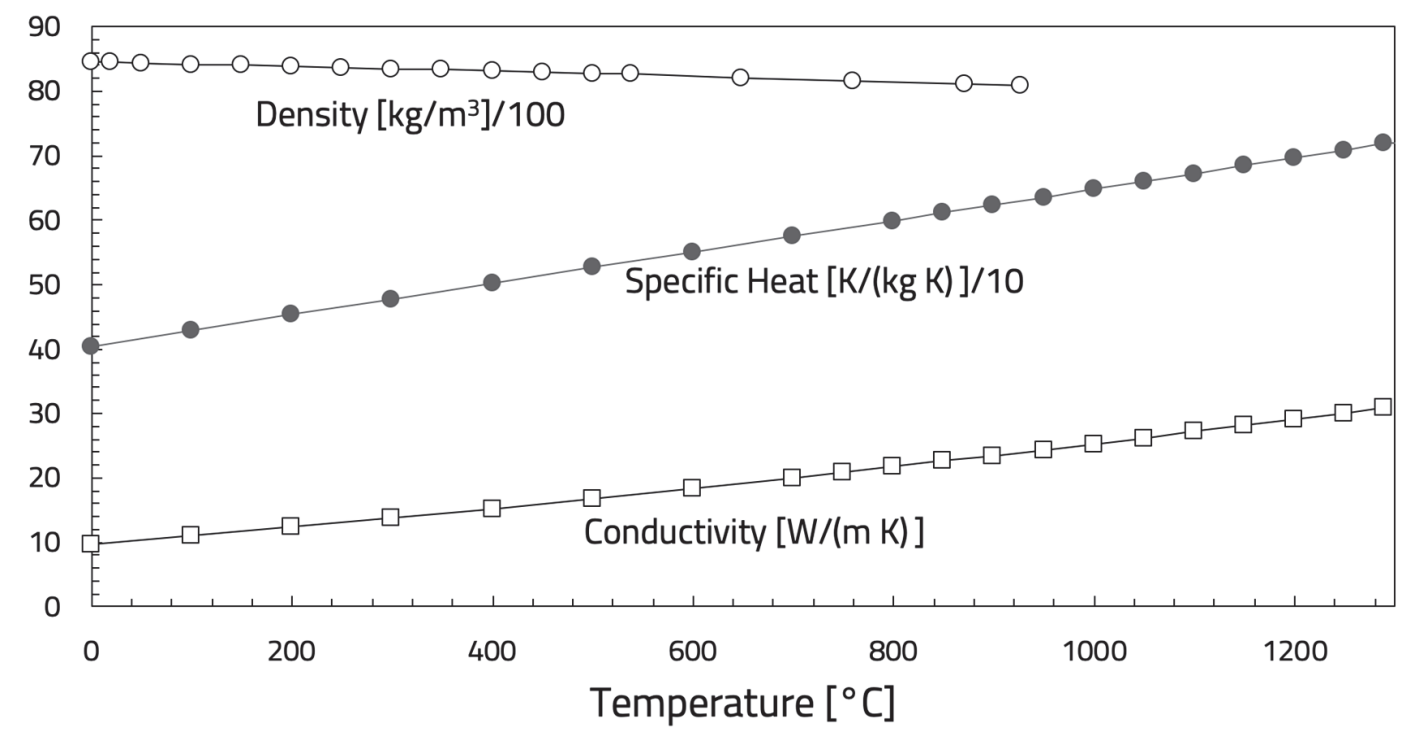

Figure 12: Thermal properties of Inconel 625 as a function of temperature

\section{NUMERICAL RESULTS}

he prediction of the FZ shape is shown in detail by the contour plot of the specimen top view in Fig. 13a and by the multiple cross sections in Fig. 13b. Experimental and numerical temperature histories in the vicinity of the middle cross section of the plate and at 2.5 and $6 \mathrm{~mm}$ far from the weld line are shown in Fig. 14. The effect of two subsequent tack welding operations could be noted from both the thermocouple data in the time frame before the EBW start. It is observed that the temperature difference measured by the thermocouples in the tack welding phase is contained. In addition, the EBW will re-melt the tack welded spots resetting the residual stress field. Comparing the results at $6 \mathrm{~mm}$, the numerical temperature peak is $376{ }^{\circ} \mathrm{C}$ versus $390{ }^{\circ} \mathrm{C}$ read by the thermocouple (Fig. 14a). On the other hand, closed to weld bead, at $2.5 \mathrm{~mm}$ far from the weld line, the numerical temperature peak is $544^{\circ} \mathrm{C}$ against the experimental value of $485^{\circ} \mathrm{C}$ (Fig. 14b). However, in both cases, the cooling rate has been successfully predicted meaning that the boundary conditions for convection and radiation are in sufficient agreement with experimental data. 
Little differences in cooling rates could be attributed to the presence of transport phenomena in the molten region that increase the heat loss and that cannot be taken into account in the phenomenological approach. Another reason could be found in the non-linearity of the emissivity coefficient that is not included for sake of simplicity in the present model. Irradiation is the primary heat transfer phenomenon at high temperature because EBW is performed in vacuum. A higher emissivity coefficient at high temperature could justify the steeper cooling rate. From the work of Palmer et al. [22] it seems more plausible that neglecting convective heat transfer in FZ is the cause of the small discrepancies in Fig. 14. Therefore, the thermal conductivity should be adjusted for temperatures that are higher than the melting temperature.

(a)
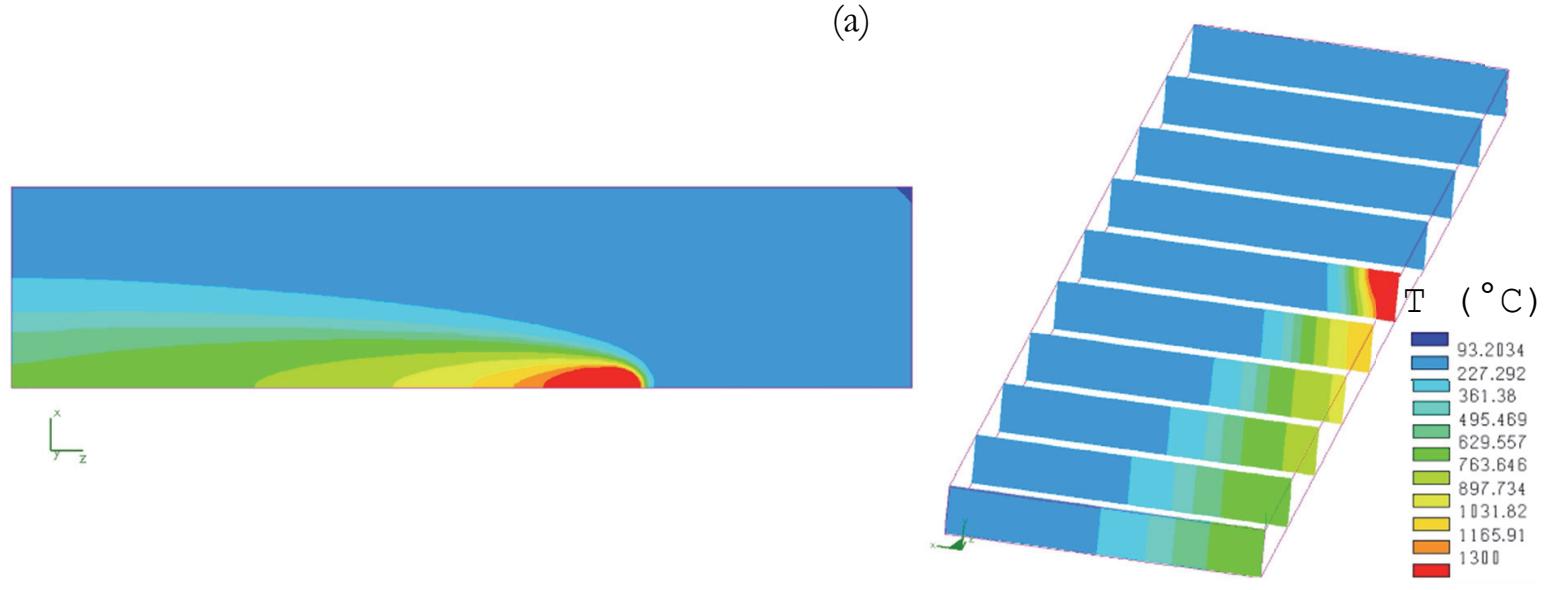

Figure 13: Top view (a) of the calculated thermal field. Cross sections (b).
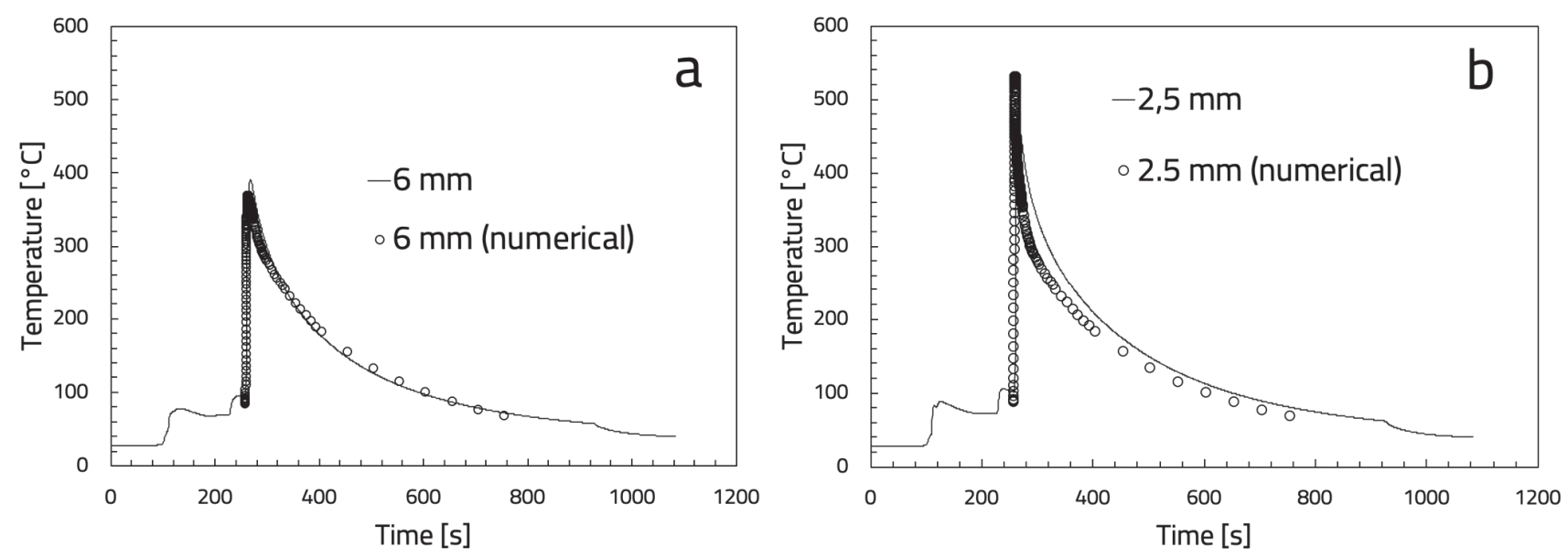

Figure 14: Comparison between numerical and experimental the temperature histories at different distance from the weld line: $6 \mathrm{~mm}$ (a), $2.5 \mathrm{~mm}$ (b).

\section{CONCLUSIONS}

A metallurgical and thermal study of Inconel 625 electron-beam welded joints was carried out. The welding parameters were first optimized in order to obtain a sound weld. The EBW didn't promote a grain grow in HAZ. Microhardness profiles didn't show any depression that may suggest a significant reduction in mechanical properties compared to that of the parent metal. Small traces of Leaves phases were detected in FZ that are thought not to affect the structural integrity of the joint. Finally, a thermal numerical model of the EBW process was developed. In order to reproduce the correct FZ shape, two different power density distribution functions have been superimposed. A 
spherical heat source in the upper part of the sheets takes into account the wide fusion zone caused by the electron beam defocalization, while a conical heat source models the penetration depth of the electron beam. Thermal numerical results have been demonstrated to be in close agreement with the experiment in terms of both FZ shape and temperature histories at different points far from the weld line.

\section{ACKNOWLEDGEMENTS}

he authors gratefully acknowledge the experimental support provided by Zanon S.p.A., Schio (VI), Italy.

\section{REFERENCES}

[1] Holcomb, D.F.A. (1989).-. Proceedings of the International Conference on Superalloys 718, 625, 706 and Derivatives, Superalloy 718-Metallurgy and Applications, The Minerals, Metals \& Materials Society, Warrendale, PA, pp. 467478.

[2] Li, Z., Gobbi, S.L., Bonollo, F., Tiziani, A., Fontana, G. (1998). Metallurgical investigation of laser welds in wrought Waspaloy, Sci. Technol. Weld. Join., 3(1), pp. 1-7.

[3] Han, W.J., Byeon, J.G., Park, K.S. (2001). Welding characteristics of the Inconel plate using a pulsed Nd: YAG laser beam, J. Mater. Process. Technol., 113(1-3), pp. 234-237.

[4] Li, Z., Gobbi, S.L., Loreau, J.H. (1997). Laser welding of Waspaloy®sheets for aero-engines, J. Mater. Process, Technol., 65(1-3), pp. 183-190.

[5] David, S.S., Babu, J.M.V. (1998). Mathematical Modeling of Weld Phenomena 4, The Institute of Materials, London, pp. 269-289.

[6] Beemer, L.J.M. (1962). Weld. J. Weld. Res. Suppl. 41, pp. 267s-273s.

[7] Roberts, H.J. Stone, J.M. Robinson, P.J. Withers, R.C. Reed, D.R. Crooke, B.J. Glassey, D.J.H. (1998). Mathematical Modeling of Weld Phenomena 4, pp. 631-640.

[8] Ferro, P., Bonollo, F., Tiziani, A. (2010). Methodologies and experimental validations of welding process numerical simulation, Int. J. Comput. Mater. Sci. Surf. Eng., 3(2-3), pp. 114-32.

[9] Klykov, N.A., Dammer, A.A., Druzhinin, A. V., Malysh, M.M. (1987). Calculations of the form of the penetration zone in laser welding using a model of two heat sources, Weld. Int., 1(10), pp. 914-916.

[10] Steen, W.M., Dowden, J., Davis, M., Kapadia, P. (1988). A point and line source model of laser keyhole welding, J. Phys. D. Appl. Phys., 21(8), pp. 1255.

[11] Rosenthal, D. (1946). The theory of moving sources of heat and its application of metal treatments, Trans. ASME, 68, pp. 849-866.

[12] Bonollo, F., Tiziani, A., Zamban, A. (1993). Model for $\mathrm{CO}_{2}$ laser welding of stainless steel, titanium, and nickel: parametric study, Mater. Sci. Technol., 9(12), pp. 1137-1144.

[13] Binda, B., Capello, E., Previtali, B. (2004). A semi-empirical model of the temperature field in the AISI 304 laser welding, J. Mater. Process. Technol., 155, pp. 1235-1241.

[14] Tsirkas, S.A., Papanikos, P., Kermanidis, T. (2003). Numerical simulation of the laser welding process in butt-joint specimens, J. Mater. Process. Technol., 134(1), pp. 59-69.

[15] Du, H., Hu, L., Liu, J., Hu, X. (2004). A study on the metal flow in full penetration laser beam welding for titanium alloy, Comput. Mater. Sci., 29(4), pp. 419-427.

[16] Feng, Z., David, S.A., Zacharia, T., Tsai, C.L. (1997). Quantification of thermomechanical conditions for weld solidification cracking, Sci. Technol. Weld. Join., 2(1), pp. 11-19.

[17] Dye, D., Hunziker, O., Reed, R.C. (2001). Numerical analysis of the weldability of superalloys, Acta Mater., 49(4), pp. 683-697.

[18] Mayor, R.A. (1976). Weld. J. Weld. Res. Suppl. 55, pp. 269s-275s.

[19] Ferro, P., Zambon, A., Bonollo, F. (2005). Investigation of electron-beam welding in wrought Inconel 706 experimental and numerical analysis, 392, pp. 94-105, DOI: 10.1016/j.msea.2004.10.039.

[20] Lacki, P., Adamus, K. (2011). Numerical simulation of the electron beam welding process, Comput. Struct., 89(1112), pp. 977-985, DOI: 10.1016/j.compstruc.2011.01.016. 
[21] Lacki, P., Adamus, K., Wieczorek, P. (2014). Theoretical and experimental analysis of thermo-mechanical phenomena during electron beam welding process, Comput. Mater. Sci., , pp. 1-10, DOI: 10.1016/j.commatsci.2014.01.027.

[22] Palmer, T.A., Elmer, J.W., Debroy, T. (2009). Heat Transfer and Fluid Flow during Electron Beam Welding of 304L Stainless Steel Alloy, ABSTRACT, 88(March).

[23] Nie, P., Ojo, O.A., Li, Z. (2014). Numerical modeling of microstructure evolution during laser additive manufacturing of a nickel-based superalloy, Acta Mater., DOI: 10.1016/j.actamat.2014.05.039.

[24] Kunidin, L. Mushongera, H.E. (2015). Acta Mater. 95, pp. 343-356.

[25] Bylya, O., Reshetov, A., Stefani, N., Rosochowska, M., Blackwell, P. (2017). Applicability of JMAK-type model for predicting microstructural evolution in nickel-based superalloys, Procedia Eng., 207, pp. 1105-1110.

[26] Reshetov, A., Bylya, O., Stefani, N., Rosochowska, M., Blackwell, P. (2016). An Approach to Microstructure Modelling in Nickel Based Superalloys. Superalloys 2016.

[27] Masoumi, F., Shahriari, D., Jahazi, M., Cormier, J., Devaux, A. (2016). Kinetics and Mechanisms of $\gamma^{\prime}$ Reprecipitation in a Ni-based Superalloy, Sci. Rep., 6, pp. 28650.

[28] Choudhury, B., Chandrasekaran, M. (2017). Investigation on welding characteristics of aerospace materials--A review, Mater. Today Proc., 4(8), pp. 7519-7526.

[29] Ferro, P. (2013). A dissolution kinetics model and its application to duplex stainless steels, Acta Mater., 61(9), pp. 3141-3147, DOI: 10.1016/j.actamat.2013.01.034.

[30] Voort, G.F. Vander., Bowman, J.W., Frank, R.B. (1994). Microstructural Characterization of Custom Age 625 Plus Alloy, pp. 489-498.

[31] Souloumiac, B., Boitout, F., Bergheau, J.M. (2002). A New Local-Global Approach for the Modelling of Welded Steel Components Distortions, Math. Model. Weld Phenom., 6, pp. 573-590.

[32] Cabibbo, M., Gariboldi, E., Spigarelli, S., Ripamonti, D. (2007). Caratterizzazione dell' evoluzione microstrutturale di una lega Ni-22Cr-12Co-9Mo A 700 E $800^{\circ} \mathrm{C}$, pp. 41-50.

[33] Mu, Y., Wang, C., Zhou, W., Zhou, L. (2018). Effect of Nb on $\delta$ Phase Precipitation and the Tensile Properties in Cast Alloy IN625, , pp. 1-9, DOI: 10.3390/met8020086.

[34] DuPont, J.N., Lippold, J.C., Kiser, S.D. (2009). Welding Metallurgy and Weldability of Nickel-Base Alloys. 